\title{
Sea Ice Proxy Working Group (SIP)
}

Eric WolfF ${ }^{1}$, A. de Vernal ${ }^{2}$ and R. Gersonde ${ }^{3}$ (co-chairs of the SIP WG)

'British Antarctic Survey, Cambridge, UK; ewwo@bas.ac.uk

2GEOTOP, Université de Québec à Montréal, Canada; ${ }^{3}$ Geosciences, Alfred-Wegener-Institute for Polar \& Marine Research, Bremerhaven, Germany

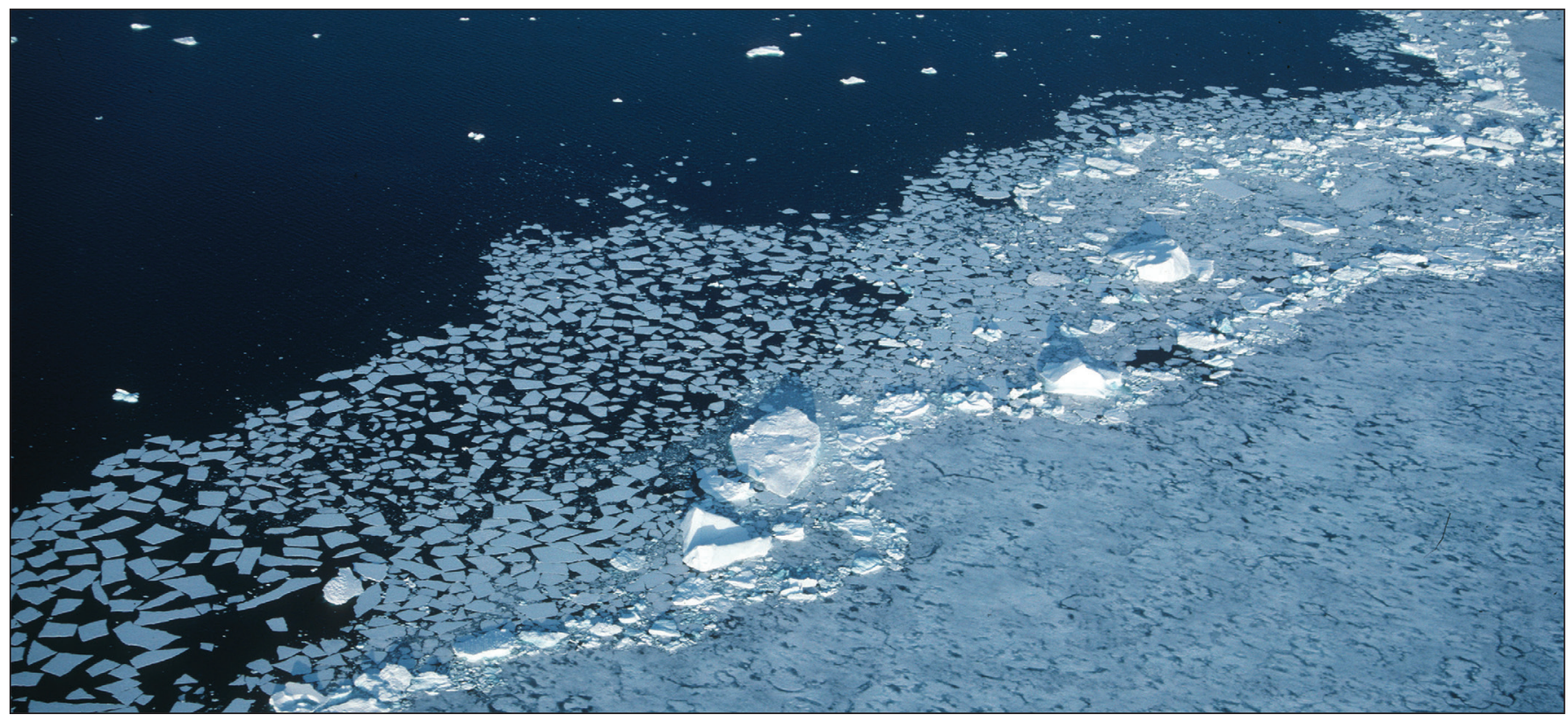

Figure 1: The edge of the pack ice in the Weddell Sea. Photo by P. Bucktrout (British Antarctic Survey, UK).

$\mathrm{T}_{\mathrm{t} \text { tise }}$ he sea ice is a crucial component of the polar climate system, and has an impact on albedo, heat and gas exchange, primary productivity and carbon export, atmospheric and ocean circulation, freshwater budget, ocean stratification, and deep water mass formation. It is therefore critical that it is correctly specified as a forcing or predicted as a feedback in modeling studies.

However, full and reliable knowledge (through satellite observation) of the area and seasonal variability of sea ice extends only to 1978. Some earlier observational data are available, but their coverage is patchy and their reliability uncertain. Proxy data are therefore critical for extending the sea-ice record to the geological past, to improve understanding of the interplay between sea ice and the climate system over a broad range of conditions.

Apart from the more intermittent (such as occurrence of terrigenous components, driftwood or whalebone) or indirect (inference of climate and hence sea ice from terrestrial data) methods, the most important sea-ice proxies are derived from marine sediments and ice cores. In the marine records, proxies such as diatom or dinoflagellate cyst assemblages and organic biomarker occurrence have been used. In ice cores, sea salt and methanesulfonic acid have been proposed as chemical proxies. However, there are uncertainties on the reliability of each proxy, and insufficient knowledge of the modern processes that control them.

PAGES has therefore set up the Sea Ice Proxies (SIP) Working Group with the objective to critically assess and compare the different proxies for sea ice, in order to make recommendations on their reliability and applicability in the Arctic and Antarctic. An extended objective will be to facilitate the production of new synthesis estimates of past sea-ice extent based on the assessed proxies.

In the Southern Hemisphere most sea-ice extent estimates from marine sediments are based on diatom assemblages from marine sediments, but different methods and species are considered and a new biomarker-based proxy (similar to the isoprenoid biomarker IP25 used in the Arctic) is under development.

In the Arctic Ocean and subarctic seas, a wide range of proxies is used in marine cores, including the occurrence of particular diatoms, dinoflagellate cysts, foraminifera and ostracodes; more recently the concentration of IP25 has become a popular proxy. In ice cores, both methanesulfonic acid and sea salt sodium have been proposed as sea ice indicators.

\section{Goals of this WG}

(i) To assess each proxy individually: What is the physical, chemical and biological basis for its use? What is the sea-ice related parameter for which it may permit reconstruction? How has it been calibrated and how robust and stationary is that calibration? In what geographical and temporal range is the proxy reliable?

(ii) Where different proxies are available, to inter-compare their findings and develop a strategy for multiproxy compilation and reconstructions.

(iii) To prepare recommendations on proxies suitable for making robust estimates of past sea ice conditions.

These methodological aspects will make up the majority of the work of the Working Group. However we will work with existing projects such as the EU Past4Future to deliver new synthesis estimates of past sea-ice extent for key time periods.

A first workshop was held at GEOTOP in Montreal, Canada in March 2012 and a separate report will be submitted summarizing that. It was aimed mainly at assessing the significance of each proxy and addressing the questions in paragraph (i) above.

A second workshop will be held in Cambridge (UK) in 2013. 